\title{
HISTÓRIAS EM QUADRINHOS COMO RECURSO METODOLÓGICO: UMA POSSIBILIDADE NAS AULAS DE EDUCAÇÃO FÍSICA
}

\author{
COMICS AS A METHODOLOGICAL RESOURCE: A POSSIBILITY IN \\ PHYSICAL EDUCATION CLASSES C
}

LAS HISTORIETAS COMO RECURSO METODOLÓGICO: UNA POSIBILIDAD EN LAS CLASES DE EDUCACIÓN FÍSICA C己

d0i)' https://doi.org/10.22456/1982-8918.105484

Kamila Isabel Trevisan* <trevisankamila6@gmail.com>

Fernando Jaime González* <fernandojaimegonzalez@gmail.com>

Robson Machado Borges* <robsonmachadoborges@gmail.com>

\footnotetext{
*Universidade Regional do Noroeste do Estado do Rio Grande do Sul. Ijuí, RS, Brasil.
}

\begin{abstract}
Resumo: Este estudo tem como objetivo descrever as consequências da implementação de três unidades de ensino utilizando histórias em quadrinhos como recurso metodológico nas aulas de Educação Física Escolar. É uma pesquisa descritiva, pautada em uma abordagem qualitativa, na qual unidades didáticas sobre lutas, ultimate frisbee e práticas corporais e saúde foram desenvolvidas em três turmas nos anos finais do ensino fundamental. Os resultados indicam que a estratégia de utilizar histórias em quadrinhos como recurso metodológico foi extremamente produtiva. Pontualmente, os alunos aprenderam sobre os temas estudados em comparação ao que sabiam anteriormente ao desenvolvimento das unidades didáticas. Especialmente os momentos de debates após a leitura das histórias em quadrinhos foram fundamentais na constituição dos conhecimentos conceituais. Na percepção dos alunos, é um recurso interessante e estimulante para estudar.
\end{abstract}

Palavras chave: Educação Física. História em quadrinhos. Conhecimento. Formação de conceitos.
Recebido em: 18-07-2020 Aprovado em: 11-11-2020 Publicado em: 26-12-2020

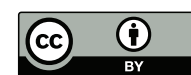

Este é um artigo publicado sob a licença Creative Commons Atribuição 4.0 Internacional (CC BY 4.0). elSSN: 1982-8918 


\section{INTRODUÇÃO}

A Educação Física (EF) é um componente curricular na escola que tem por tradição a ênfase na reprodução de ações técnicas de algumas modalidades esportivas. Todavia, essa concepção vem sendo discutida e alterada - mesmo que lentamente - de modo que na contemporaneidade a Base Nacional Comum Curricular (BNCC) aponta sua especificidade vinculada à tematização das "[...] práticas corporais em suas diversas formas de codificação e significação social, entendidas como manifestações das possibilidades expressivas dos sujeitos, produzidas por diversos grupos sociais no decorrer da história" (BRASIL, 2017, p. 213), tais como: lutas, esportes, práticas corporais e saúde, práticas corporais junto à natureza, ginástica, entre outras (GONZÁLEZ; FRAGA, 2009).

Nessa linha, é necessário que os temas de responsabilidade da EF sejam tematizados não somente na perspectiva procedimental - saber fazer-, mas também nas dimensões conceitual - saber sobre ${ }^{1}$ - e atitudinal - saber ser - durante as aulas (DARIDO, 2012). Um aprofundamento que reforça essa ideia é apresentado na BNCC ao apontar oito dimensões de conhecimento na EF: experimentação, uso e apropriação, fruição, reflexão sobre a ação, construção de valores, análise, compreensão e protagonismo comunitário.

No processo de abordagem da pluralidade de temas específicos da EF Escolar, os professores optam por métodos ${ }^{2}$ ou estratégias de ensino para desenvolver seu trabalho. Quando se trata do ensino da dimensão conceitual dos conteúdos, que é complexo e exige reflexão dos alunos, torna-se interessante a utilização de recursos metodológicos que auxiliem na compreensão, por exemplo: a confecção de mapas conceituais (MALDONADO et al., 2014), o compartilhamento de informações em redes sociais como o Facebook (VARGAS; MORISSO; GONZÁLEZ, 2017), o uso de hemeroteca, pesquisa em sites, confecção de livros, textos e resumos, trabalhos em grupos, exposições, debates, organização de painéis (DARIDO; SOUZA JÚNIOR, 2013), jogos digitais, jornais on-line, criação e análise de blogs, utilização de vídeos (BETTI, 2001), produções de sínteses escritas, registros e anotações no caderno da disciplina, confecção de fichas sobre diferentes conteúdos, apresentação de seminários, júri simulado, análise de charges, indagações (GONZÁLEZ; BRACHT, 2012), história em quadrinhos (FABRI, 2017), entre outros.

Particularmente, as histórias em quadrinhos são interessantes por apresentar uma linguagem de fácil compreensão, juntamente com imagens que representam a ação da fala e a adaptação a diferentes faixas etárias. Logo, pode ser um instrumento de ensino bastante pertinente. Como lembra Vergueiro (2016), a leitura dos quadrinhos é muito popular entre os alunos, podendo aumentar sua motivação para o estudo dos conteúdos. Mais especificamente, a combinação da escrita com a imagem e a

1 González e Fraga (2012) apresentam uma divisão da dimensão conceitual em conhecimento técnico e conhecimento crítico. O técnico abrange os assuntos que permitem entender as características e o funcionamento de determinada prática corporal, em relação a sua lógica interna. O crítico corresponde a assuntos que possibilitam analisar o contexto sociocultural de uma prática corporal, analisando a sua relação com a sociedade num contexto mais amplo. 
diversidade de enredos possíveis tornam os quadrinhos um produto sedutor para o público infantojuvenil, o que realça o seu potencial para educar na escola (SOUSA et al., 2019).

De acordo com Vergueiro (2016), as primeiras produções de histórias em quadrinhos surgiram no fim do século XIX nos Estados Unidos e tinham suas publicações feitas em jornais. Pontualmente, Cavalcante, Novais e Ferreira (2019) apontam que os quadrinhos surgiram como gênero em 1895, por ocasião da criação da tirinha The Yellow Kid, publicada em Nova York por Richard Outcault.

Inicialmente, os quadrinhos possuíam um caráter cômico. Porém, após ganharem um espaço diário em um veículo de comunicação, passaram a abordar outros temas que envolviam a família, animais antropomorfizados e protagonistas femininas. Por ser uma forma de entretenimento peculiar em relação às demais (folhetins, rádio, cinema, entre outras), os quadrinhos foram "[...] levados a todo mundo pelos sindycates, grandes organizações distribuidoras de notícias e material de entretenimento para jornais de todo o planeta [...]" (VERGUEIRO, 2016, p. 10). Com isso, ganharam espaço no meio da comunicação, sendo que sua popularidade multiplicou após a Segunda Guerra Mundial, em que heróis eram retratados em conflitos bélicos (VERGUEIRO, 2016). Destacadamente, histórias de super-heróis como Superman e Batman produziram uma grande revolução dos quadrinhos (CAVALCANTE; NOVAIS; FERREIRA, 2019).

Conforme levantamento de Carvalho (2006), os primeiros estudos que buscaram avaliar a apreciação dos quadrinhos em jornais foram realizados nos Estados Unidos, na década de 1960. Os resultados indicavam que dos 2,5 bilhões de leitores dos principais jornais da época, mais de $75 \%$ acompanhavam diariamente as tiras em quadrinhos.

Segundo Vergueiro (2016), as primeiras histórias em quadrinhos voltadas para a educação apareceram na década de 1940, nos Estados Unidos. Os primeiros movimentos para introduzir este gênero de linguagem na escola estavam ligados ao ensino da história e literatura.

\begin{abstract}
Nesse sentido a percepção de que as Histórias em Quadrinhos podiam ser utilizadas de forma eficiente para a transmissão de conhecimentos específicos, ou seja, desempenhando uma função utilitária e não apenas de entretenimento, já era corrente no meio 'quadrinhístico' desde muito antes de seu descobrimento pelos estudiosos da comunicação. As primeiras revistas em quadrinhos de caráter educacional publicadas nos Estados Unidos [...] traziam antologias de histórias em quadrinhos sobre personagens famosos da história, figuras literárias e eventos históricos (VERGUEIRO, 2016, p. 17).
\end{abstract}

No Brasil os quadrinhos começaram a ser estudados no meio acadêmico ao final da década de 1960 (XAVIER, 2018). Com o passar dos anos este gênero ganhou espaço no ambiente escolar. Os Parâmetros Curriculares Nacionais ( $P C N$ ) (BRASIL, 1997) e o Programa Nacional da Biblioteca na Escola (PNBE) de 1997 auxiliaram neste processo. Pontualmente, os PCN apresentam os quadrinhos como um gênero a ser interpretado por Artes e Língua Portuguesa. O PNBE incluiu os quadrinhos em sua relação para compra de livros a partir de 2006 (VERGUEIRO; 
RAMOS, 2013). Mais recentemente, a BNCC e alguns referenciais curriculares estaduais propostos a partir da Base - como o Referencial Curricular Gaúcho (RIO GRANDE DO SUL, 2018), por exemplo - mencionam as histórias em quadrinhos como recurso metodológico em Arte, Língua Portuguesa e Língua Inglesa (BRASIL, 2017).

Não obstante, Sousa et al. (2019) salientam que por meio das histórias em quadrinhos é possível abordar diferentes assuntos em qualquer disciplina ou nível de ensino. Pesquisas realizadas em diferentes áreas do conhecimento (FALLEIRO; BITTENCOURT, 2001; COELHO, 2005; CARVALHO; MARTINS, 2009; BLUM; MOELLWALD, 2017, entre outros) oferecem suporte para tal afirmação, evidenciando a utilização dos quadrinhos no ensino de vários componentes curriculares em diferentes níveis de escolarização, fazendo deste gênero literário - inicialmente considerado uma forma de entretenimento - também um recurso de ensino. Afinal, trata-se de um recurso de fácil manipulação que permite adaptar a linguagem à idade dos alunos e alterar as imagens e ações dos personagens conforme o conteúdo trabalhado.

Especificamente, as histórias em quadrinhos voltadas para a EF começaram a fazer parte do contexto escolar na década de 1970, com a intenção de estimular jovens de 7 a 14 anos a praticar esportes. Para tanto, o governo federal criou histórias de um personagem chamado "Dedinho", que praticava diferentes modalidades esportivas, como atletismo, voleibol, basquetebol (PINTO, 2003), como a Figura 1 ilustra.

Figura 1 - Capas da revista Dedinho

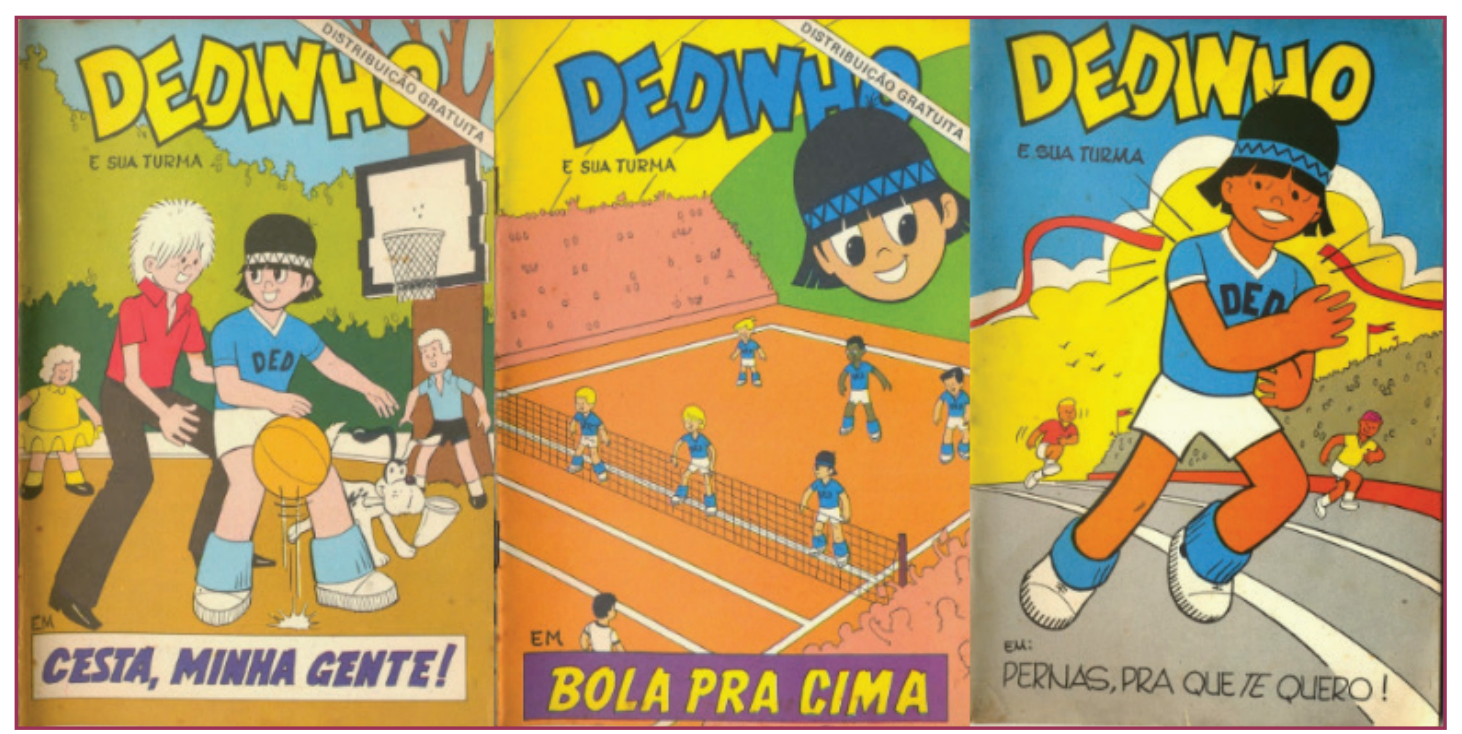

Fonte: Museu dos gibis $(2014$, p. 1)

Nos últimos anos, diversas pesquisas têm apontado o potencial metodológico da utilização de histórias em quadrinhos nas aulas de EF Escolar (REBOLHO; CASAROTTO; JOÃO, 2009; LIRA NETO; ALMEIDA, 2010; AMARAL; CARVALHO; RIBEIRO, 2014; FABRI, 2017; LOPES DA SILVA et al., 2019, entre outros). Em comum, os resultados dos estudos destacam a atratividade que os quadrinhos representam em relação aos demais recursos, como textos sem imagens e livros 
didáticos, por exemplo. Como Rebolho, Casarotto e João (2009, p. 49) afirmam: “[...] a facilidade com que a história em quadrinhos comunica conhecimentos científicos está relacionada ao fato de que ela transmite informações de forma atrativa, divertida e facilita a memorização de conceitos".

Considerando, por um lado, que as histórias em quadrinhos podem ser úteis para abordar a dimensão conceitual de conteúdos relacionados à cultura corporal de movimento e, por outro, que a utilização dos quadrinhos não é algo frequente na $E F$, desenvolvemos este estudo com o objetivo de descrever as consequências da implementação de três unidades de ensino utilizando histórias em quadrinhos como recurso metodológico nas aulas de EF Escolar.

\section{PROCEDIMENTOS METODOLÓGICOS}

Esta pesquisa consiste na análise do desenvolvimento de três unidades de ensino ${ }^{3}$ - sobre lutas, ultimate frisbee e práticas corporais e saúde - para turmas dos anos finais do ensino fundamental, por meio da utilização de histórias em quadrinhos. Para tanto, pautamo-nos em uma abordagem qualitativa, do tipo descritiva. Segundo Gil (2002, p. 42), "[...] as pesquisas descritivas têm como objetivo primordial a descrição das características de determinada população ou fenômeno ou, então, o estabelecimento de relações entre variáveis".

O estudo foi desenvolvido em uma escola da rede pública de ensino de uma cidade da região noroeste do estado do Rio Grande do Sul. Teve como sujeitos participantes 43 alunos, com idades entre 11 e 14 anos, com situação socioeconômica de média e baixa renda. A opção por desenvolver a pesquisa com os alunos desta escola ocorreu pelo fato de que nessa instituição as aulas de EF são propostas de acordo com um currículo pautado na perspectiva da cultura corporal de movimento. Sendo assim, os discentes compreendem a EF como uma disciplina que aborda vários temas além de modalidades esportivas.

Nessa linha, a definição das turmas foi realizada em alinhamento aos assuntos previstos no currículo da escola. As unidades didáticas ${ }^{4}$ tiveram como foco a dimensão conceitual dos conteúdos e foram tematizadas com a seguinte organização: dez aulas sobre lutas com uma turma do $7^{\circ}$ ano; 12 aulas sobre ultimate frisbee com a outra turma do $7^{\circ}$ ano; e dez aulas sobre práticas corporais e saúde com o $8^{\circ}$ ano ${ }^{5}$. Na sequência, apresentamos o Quadro 1 explicitando os conteúdos e os objetivos de aprendizagem de cada unidade didática/aula.

\footnotetext{
3 Unidade de ensino é entendida neste estudo como todo o processo de organização, do início ao final do planejamento, para o ensino de um tema específico. Assim, uma unidade de ensino é composta de: realização do diagnóstico, confecção de uma unidade didática, criação de planos de aula e avaliação do aprendizado dos alunos.

4 Unidade didática é entendida neste estudo como a organização dos conteúdos a serem ensinados em um determinado período de tempo.

5 As unidades didáticas foram desenvolvidas nas aulas de uma professora de EF, sendo que este estudo não foi apreciado por um Comitê de Ética. Contudo, declaramos que todos os procedimentos éticos que constam nas resoluções foram integralmente contemplados de modo que as identidades dos participantes não são divulgadas em nenhum momento do texto.
} 
Quadro 1 - Conteúdos e o objetivos de aprendizagem em cada aula das respectivas unidades didáticas

\begin{tabular}{|c|c|c|c|}
\hline $\begin{array}{l}\text { Unidade } \\
\text { didática }\end{array}$ & Aula & Conteúdo & Objetivo \\
\hline \multirow{7}{*}{ Lutas } & 1 & História das lutas corporais & $\begin{array}{l}\text { Conhecer a história das lutas corporais e } \\
\text { seus contextos }\end{array}$ \\
\hline & 2 e 3 & Características gerais das lutas & $\begin{array}{l}\text { Compreender as características gerais } \\
\text { das lutas }\end{array}$ \\
\hline & 4 & Diferença entre lutas e brigas & $\begin{array}{c}\text { Compreender a diferença entre lutas e } \\
\text { brigas }\end{array}$ \\
\hline & 5 e 6 & Lutas de curta distância & $\begin{array}{l}\text { Compreender e vivenciar corporalmente } \\
\text { lutas de curta distância }\end{array}$ \\
\hline & 7 & Lutas de média distância & $\begin{array}{l}\text { Compreender e vivenciar corporalmente } \\
\text { lutas de média distância }\end{array}$ \\
\hline & 8 e 9 & Lutas de longa distância & $\begin{array}{l}\text { Compreender e vivenciar corporalmente } \\
\text { lutas de longa distância }\end{array}$ \\
\hline & 10 & \multicolumn{2}{|c|}{ Avaliação escrita sobre os assuntos abordados } \\
\hline \multirow{6}{*}{$\begin{array}{l}\text { Ultimate } \\
\text { frisbee }\end{array}$} & 1 e 2 & $\begin{array}{c}\text { História e regras do ultimate } \\
\text { frisbee }\end{array}$ & $\begin{array}{c}\text { Conhecer o contexto histórico do ultimate } \\
\text { frisbee e suas regras }\end{array}$ \\
\hline & 3 e 4 & Classificação do ultimate frisbee & $\begin{array}{l}\text { Compreender o ultimate frisbee como } \\
\text { esporte de invasão }\end{array}$ \\
\hline & 5 e 6 & $\begin{array}{l}\text { Igualdade de direito entre os } \\
\text { gêneros no ultimate frisbee }\end{array}$ & $\begin{array}{c}\text { Compreender a igualdade de direitos } \\
\text { entre os gêneros na prática do ultimate } \\
\text { frisbee }\end{array}$ \\
\hline & 7 e 8 & Inclusão nos esportes & $\begin{array}{c}\text { Compreender o processo de inclusão no } \\
\text { ultimate frisbee e a relação de exclusão } \\
\text { nas práticas corporais no ambiente } \\
\text { escolar }\end{array}$ \\
\hline & 9 e 10 & $\begin{array}{c}\text { Relação de consumo financeiro } \\
\text { dos esportes e comércio de } \\
\text { produtos esportivos }\end{array}$ & $\begin{array}{c}\text { Compreender a diferença de consumo } \\
\text { financeiro dos esportes e comércio de } \\
\text { produtos esportivos }\end{array}$ \\
\hline & 11 e 12 & \multicolumn{2}{|c|}{ Avaliação escrita sobre os assuntos abordados } \\
\hline \multirow{5}{*}{$\begin{array}{l}\text { Práticas } \\
\text { corporais } \\
\text { e saúde }\end{array}$} & 1 e 2 & Conceitos de saúde & Conhecer conceitos de saúde \\
\hline & 3 e 4 & $\begin{array}{c}\text { Fator socioeconômico e seu } \\
\text { vínculo com a saúde }\end{array}$ & $\begin{array}{l}\text { Compreender a influência dos fatores } \\
\text { socioeconômicos na saúde }\end{array}$ \\
\hline & 5 e 6 & Exercícios aeróbios e anaeróbios & $\begin{array}{c}\text { Compreender a diferença dos exercícios } \\
\text { físicos aeróbios e anaeróbios }\end{array}$ \\
\hline & 7 e 8 & O uso de anabolizantes & $\begin{array}{l}\text { Compreender os riscos ao utilizar } \\
\text { anabolizantes }\end{array}$ \\
\hline & 9 e 10 & \multicolumn{2}{|c|}{ Avaliação escrita sobre os assuntos abordados } \\
\hline
\end{tabular}

Fonte: os autores (2020)

Após a definição dos objetivos, e considerando a ênfase na dimensão conceitual dos conteúdos, entendemos que seria pertinente utilizar um recurso metodológico que possibilitasse aos alunos desempenhar um papel ativo nas aulas, na perspectiva das metodologias ativas. Assim, após uma conversa diagnóstica para identificar o interesse dos alunos sobre possíveis recursos metodológicos, uma parte considerável dos discentes mencionou o gosto por histórias em quadrinhos. Essa ação permitiu-nos identificar uma forma metodológica que pode ser prazerosa e ir ao encontro do mundo dos alunos, como propõem Sousa et al. (2019). A partir disso, produzimos diversas histórias em quadrinhos para o ensino nas aulas de EF. 
Para desenvolver os objetivos propostos, as aulas foram planejadas observando um método de ensino composto de seis partes. Na sequência consta a descrição da especificidade de cada momento:

- Roda Inicial: introdução da aula. Explicação sobre o conteúdo do dia.

- Questionamentos: realização de indagações aos alunos para identificar o que sabiam sobre o assunto a ser estudado.

- Leitura dos quadrinhos: os discentes realizam leitura de histórias em quadrinhos.

- Debate: os alunos são estimulados a dialogar com os colegas sobre o que entenderam da leitura. Pode haver posicionamentos concordantes ou discordantes, com base em argumentos para justificar as opiniões.

- Tarefa: os discentes realizam tarefas envolvendo práticas corporais/motoras e/ou teórico-conceituais, dependendo do conteúdo estudado.

- Roda Final: conversa com os alunos sobre o desenvolvimento da aula, refletindo acerca dos assuntos abordados. Sua representação está na Figura 2

Figura 2 - Método de ensino utilizado

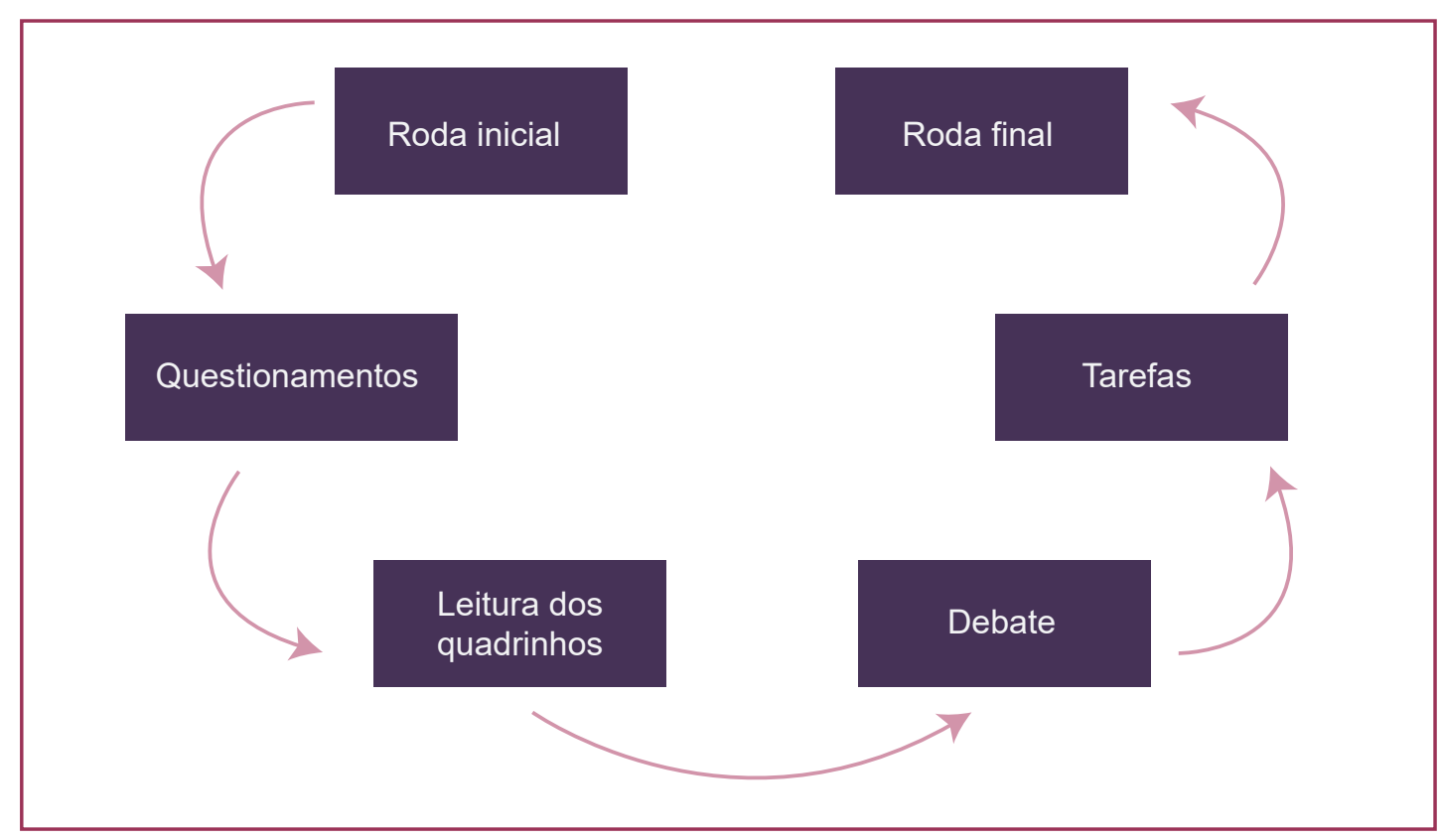

Fonte: os autores (2020)

Para abordar os conteúdos mencionados nas unidades didáticas, criamos histórias em quadrinhos de acordo com o número de objetivos estabelecidos para as aulas. Assim, confeccionamos seis histórias em quadrinhos para a unidade didática de lutas, cinco para ultimate frisbee e quatro para práticas corporais e saúde. Especificamente, na produção das histórias em quadrinhos utilizamos um programa on-line chamado Pixton ${ }^{6}$, que permite a criação de cenários, personagens e diferentes formas de escrita por meio de opções de diálogos. Como exemplo, apresentamos trechos de histórias em quadrinhos utilizadas nas aulas, contemplando os três temas abordados. Assim, no Quadro 2 o tema é lutas.

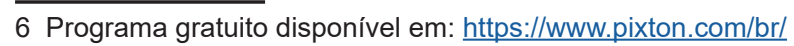


Quadro 2 - Histórias em quadrinhos sobre lutas

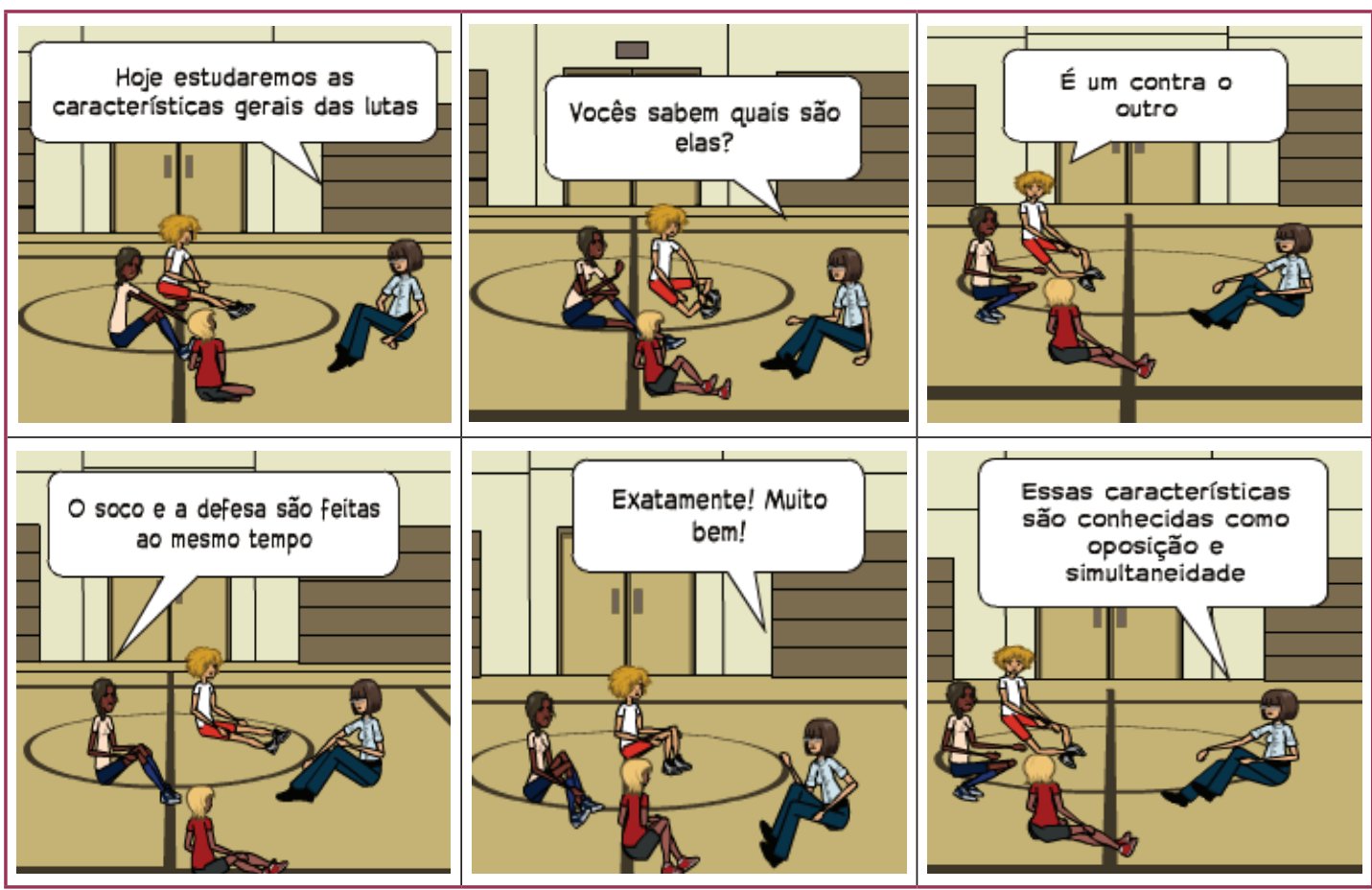

Fonte: os autores (2020)

Continuando, no Quadro 3 o tema é frisbee:

Quadro 3 - Histórias em quadrinhos sobre ultimate frisbee

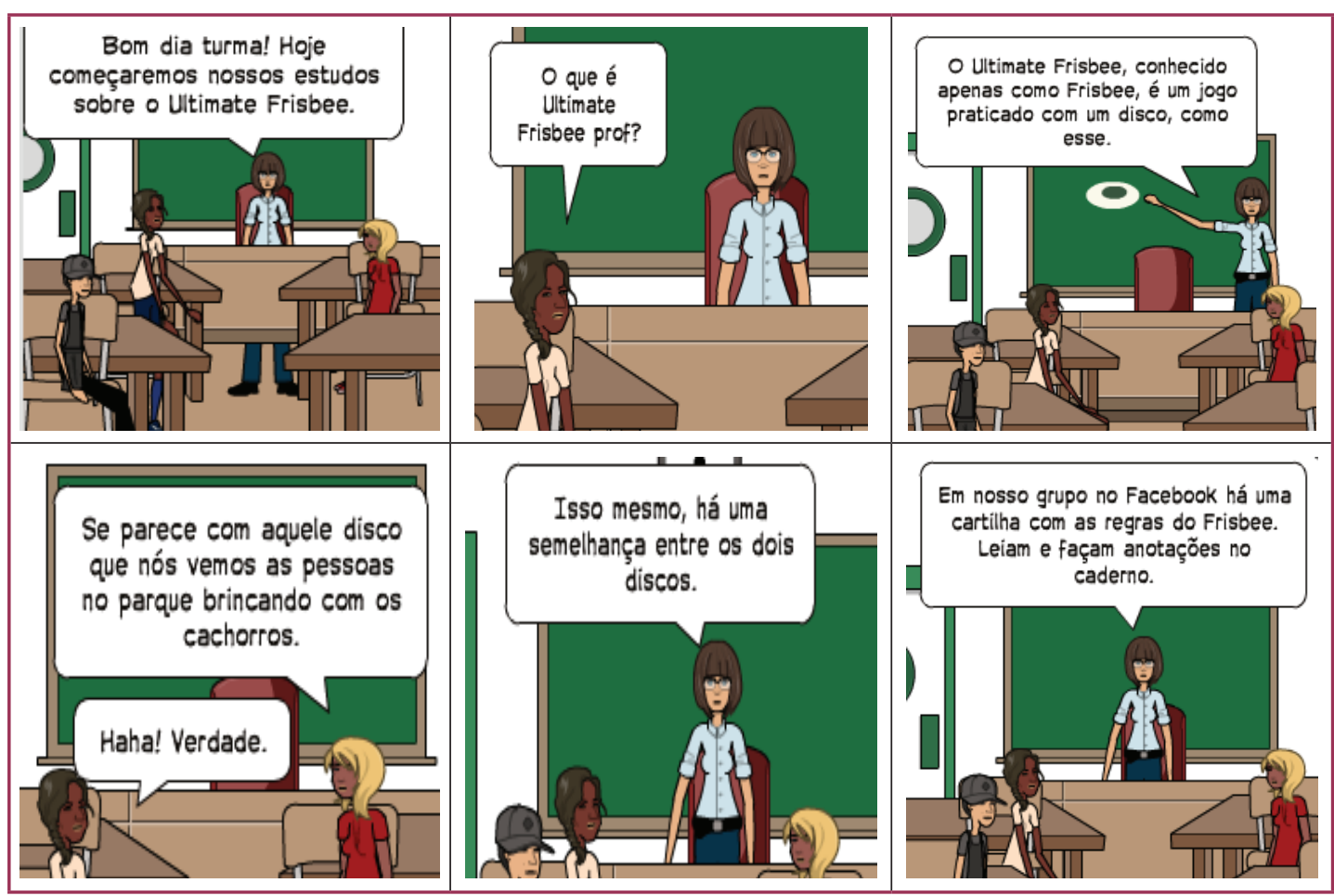

Fonte: os autores (2020)

E no Quadro 4 o tema é práticas corporais e saúde 
Quadro 4 - Histórias em quadrinhos sobre práticas corporais e saúde.

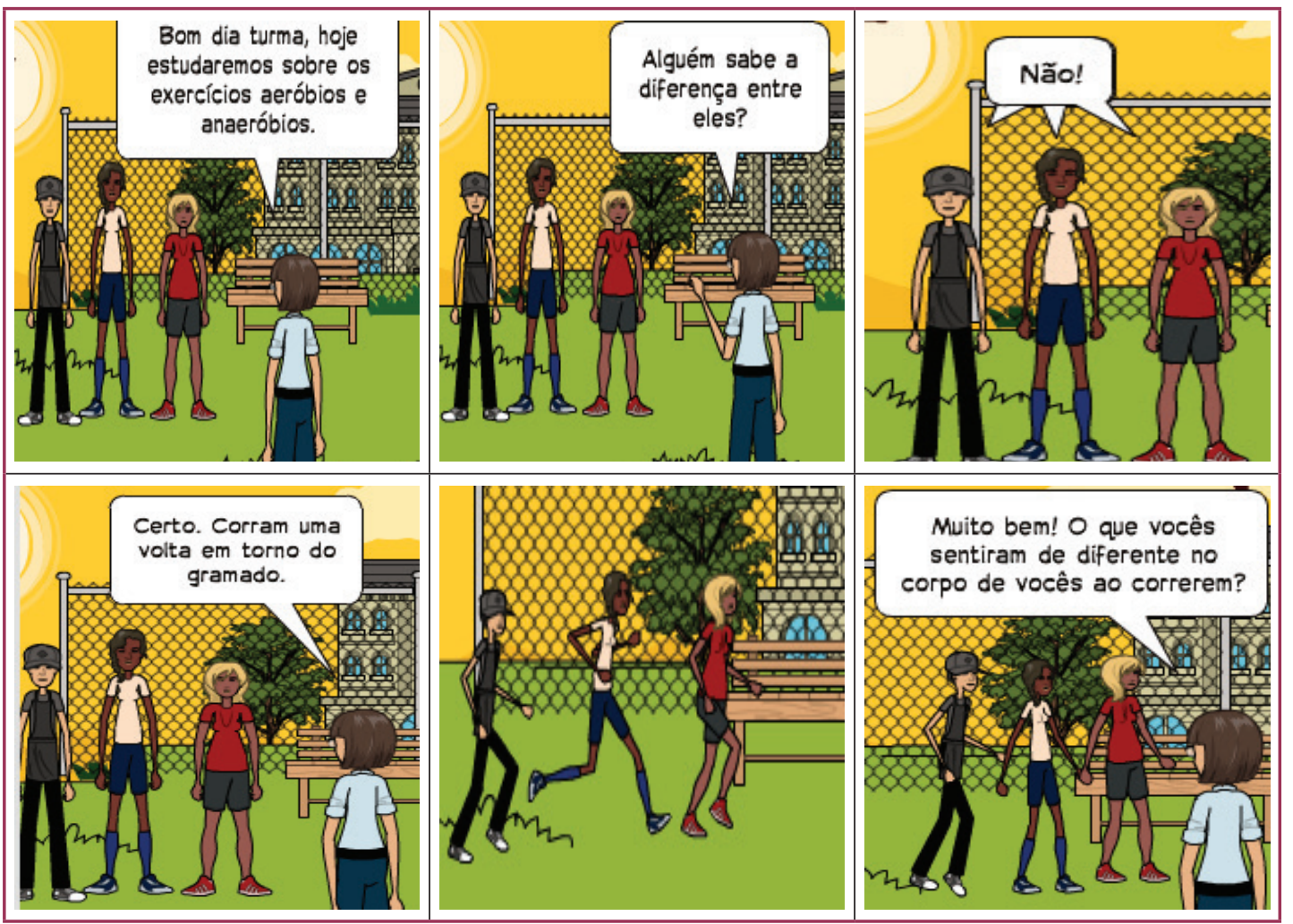

Fonte: os autores (2020)

\section{ANÁLISE DOS DADOS E DISCUSSÃO DOS RESULTADOS}

No processo de análise dos dados, pautamo-nos nas anotações feitas pelos alunos ao final de cada leitura dos quadrinhos, sobre o conteúdo que havia sido abordado em aula, nas avaliações escritas realizadas ao final de cada unidade didática e nas falas dos alunos gravadas em áudios.

Com base na perspectiva da análise de conteúdo (BARDIN, 2011), optamos por apresentar nossas interpretações organizadas em quatro categorias": a) "É aquele disco que joga pra cachorro?": o primeiro contato com determinados temas; b) "A gente compreende bem melhor as coisas": o aprendizado dos alunos sobre os temas estudados com a utilização das histórias em quadrinhos; c) "Foi uma coisa diferente porque nós nunca estamos em grupo e debatemos, isso é raro": os momentos de debates sobre a leitura das histórias em quadrinhos como elemento constituidor de conhecimento; d) Do "deixa eu ler essa coisa" para o "gostei dessa prática de aula com histórias em quadrinhos": a percepção dos alunos acerca do recurso de ensino com o passar das aulas.

Em relação à primeira categoria, identificamos que os alunos não haviam tido, anteriormente, os temas estudados nas unidades didáticas desenvolvidas. Logo, trata-se de um primeiro contato com determinados conteúdos, como se percebe nos seguintes comentários ocorridos durante as aulas iniciais: "Eu só vi em filme esse prato de atirar" (Aluna 1 - Primeira aula sobre ultimate frisbee); "É muito legal essa atividade do frisbee, não sabia que tinha esse jogo" (Aluna 2 - Primeira aula sobre ultimate frisbee); "[...] eu nunca tinha visto isso" (Aluno 24 - Primeira aula sobre

7 Para isso, utilizamos metáforas com trechos das falas dos alunos durante as aulas. Essas falas não foram mencionadas, novamente, na descrição das análises para que o texto não ficasse repetitivo. 
práticas corporais e saúde); "[...] eu nunca tinha aprendido essas coisas, sabe?" (Aluno 43 - Primeira aula sobre lutas); "Não, sobre saúde não, a gente estudou sobre voleibol, basquete um pouco [...]" (Aluno 16 - Primeira aula sobre práticas corporais e saúde) $)^{8}$. Além disso, quando perguntamos se os alunos haviam tido aulas sobre lutas na $E F$, eles responderam negativamente.

Em relação a isso, ainda se percebe que a abordagem de temas para além dos esportes tradicionais nas aulas de EF não é algo majoritário nas escolas. Como Silva e Sampaio (2012) apontam, os esportes populares

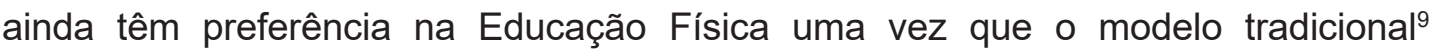
é uma forma de atuação bastante presente nessa disciplina escolar (FENSTERSEIFER, 2016). Assim, mesmo se tratando de uma escola que tem apresentado temas para além dos esportes tradicionais nos últimos anos, os alunos ainda não tinham experimentado os três temas que abordamos nas intervenções mencionadas.

Ao analisar a segunda categoria, verificamos que os alunos aprenderam sobre os temas estudados em comparação ao que sabiam anteriormente ao desenvolvimento das unidades didáticas. Esse aprendizado conceitual, por meio da leitura das histórias em quadrinhos, está vinculado tanto ao conhecimento técnico quanto ao crítico na perspectiva do que é apresentado por González e Fraga (2012). Identificamos esse achado voltado para o conhecimento técnico por meio de manifestações dos alunos, tais como: "Distância curta é quando o seu oponente está perto de você e você o agarra, a intenção é agarrar" (Aluno 38 - Quarta aula sobre lutas); "Esportes com interação: são esportes em que o adversário pode interferir na sua ação, eles podem tomar a bola na sua vez de atacar (fazer o gol)" (Aluno 6 - Segunda aula sobre ultimate frisbee); "É quando o oponente não pode dar soco nem chute, porque eles ficam muito longe, por isso usam a espada" (Aluno 37 - Sexta aula sobre lutas); "Brigas só pensam em bater, sem saber o que vai acontecer, se vai morrer" (Aluno 32 - Terceira aula sobre lutas); "Ele é usado nas academias (anabolizante) para criar massa muscular, tem vários problemas, o que me chamou atenção foi a impotência sexual, a calvície e a agressividade" (Aluno 19 - Quinta aula sobre práticas corporais e saúde).

As manifestações dos alunos indicam o caráter verossímil da afirmação de Vergueiro (2016), quando o autor defende a possibilidade de aprendizado de conteúdos através da leitura de histórias em quadrinhos. Com esse recurso, as informações são absorvidas na própria linguagem do aluno, sem precisar, muitas vezes, da explicação demorada do professor. Assim, o estudante não precisa ter contato anterior com o tema para entendê-lo, pois os quadrinhos possuem um caráter globalizador e sua linguagem pode ser adaptada conforme o nível de escolaridade (VERGUEIRO, 2016).

Nessa linha, Lira Neto e Almeida (2010) também identificaram o aprendizado dos alunos por meio de histórias em quadrinhos. Os autores utilizaram um gibi da Turma da Mônica para abordar a cerimônia da Tocha Olímpica. Com isso, os discentes aprenderam o significado da cerimônia, a época na qual surgiu e o sentido que possui atualmente.

8 Visando a uma análise que fizesse referência aos temas abordados nas três intervenções que originaram os dados, na apresentação de trechos das falas dos alunos optamos por contemplar falas proferidas em aulas de diferentes unidades didáticas.

9 Pelo termo modo tradicional, entende-se o ensino de poucas modalidades esportivas (geralmente, não mais do que quatro durante o ano) pautado na execução e reprodução de gestos motores. 
Do mesmo modo, a constituição de saberes relacionados ao conhecimento conceitual crítico foi possível com a leitura dos quadrinhos, como se percebe: "O uso excessivo dos anabolizantes pode causar alguns efeitos colaterais, mas também é bom porque é usado como uso medicinal" (Aluna 28 - Quinta aula sobre práticas corporais e saúde); "Eu aprendi hoje sobre as vendas que utilizam imagens de jogadores famosos Cristiano Ronaldo, Neymar, Messi e outros jogadores para vender mais produtos" (Aluno 5 - Quinta aula sobre ultimate frisbee);

\begin{abstract}
No dia 23 falamos na aula sobre o conceito de saúde que fala sobre as condições de trabalho. Falamos também sobre moradia que se fôssemos observar as condições de moradia em uma casa em Copacabana de uma pessoa mais rica são melhores, pois a água é tratada, tem esgoto [saneamento]... Já as de periferia não, muitas vezes, as condições são péssimas, a água não é tratada, tem muito lixo (Aluna 27- Primeira aula sobre práticas corporais e saúde).
\end{abstract}

Este dado é similar ao encontrado por Lopes da Silva et al. (2019), ao analisarem uma experiência pedagógica no ensino fundamental com o uso de histórias em quadrinhos nas aulas de EF. Conforme os autores, a partir da intervenção realizada, os discentes passaram a identificar aspectos vinculados ao conhecimento conceitual crítico sobre conteúdos pertinentes à EF, como a participação feminina em histórias em quadrinhos e padrões de beleza corporal. Logo, se os saberes vinculados à dimensão conceitual dos conteúdos correspondem a um dos aspectos indicados pela BNCC para serem contemplados nas aulas de EF, as histórias em quadrinhos se constituem como um excelente recurso para esse propósito. Afinal, como Lopes da Silva et al. (2019) indicam, o uso de quadrinhos no ensino pode ajudar a desenvolver o aprendizado crítico de uma forma mais prazerosa.

Destacadamente, percebemos que as histórias em quadrinhos possibilitaram a constituição de significados para os alunos à medida que eles conseguiram relacionar os conteúdos estudados com situações presentes em seu cotidiano. Algumas falas dos alunos durante as aulas evidenciam esse entendimento: "É, professora, meu tio trabalhava na construção de uma casa, daí ele caiu do andaime e quebrou o braço, ficou um tempo sem trabalhar e quando voltou sentia dor para carregar o carrinho de mão com massa (de cimento), interferiu na saúde dele, o acidente" (Aluno 23 Segunda aula sobre práticas corporais e saúde); "Professora, a senhora sabia que meu tio morreu numa briga? Eles brigaram com facão, o outro só se machucou" (Aluno 34 - Terceira aula sobre lutas).

Essa relação dos assuntos estudados em aula, por meio das histórias em quadrinhos, com acontecimentos na vida dos alunos também foi registrada por Sousa et al. (2019). Como os autores destacam, os quadrinhos permitem uma releitura de cenas e linguagens do cotidiano relacionadas à realidade dos estudantes. Além disso, a constituição de significados para os discentes, através de quadrinhos, também foi identificada no estudo de Fabri (2017). Mediante a construção de histórias em quadrinhos, a autora identificou que crianças, adolescentes e jovens de um projeto social constituíram profícuos momentos de aprendizagens e de experiências sobre a exclusão e o preconceito nas práticas corporais.

Passando para a análise da terceira categoria, compreendemos que os debates, após a leitura das histórias em quadrinhos, foram fundamentais na constituição dos 
conhecimentosapresentadosnacategoriaanterior, consistindonummomentodestacado deaprendizado durante as aulas. Ao debater, os alunos puderam comparar e relacionar a interpretação pessoal da leitura com a dos colegas, como fica claro no seguinte diálogo ${ }^{10}$ durante a quarta aula da unidade didática sobre ultimate frisbee:

- Tem um cara que criou uma clínica para ajudar as pessoas. (Aluna 12)

- Para as pessoas que vinham da guerra, para pessoas que tinham limitações. (Aluna 9)

- E se pensar não são só os que têm limitação que são excluídos, os normais também. (Aluna 8)

- E também, às vezes eles excluem os que têm limitações, do jogo, deixam por último pra escolher.

(Aluna 2)

- É só para fechar time. (Aluna 9)

Como se percebe no diálogo, o momento de debate possibilitou um aprendizado sobre o tema em estudo de modo que após a leitura dos quadrinhos a Aluna 12 compreendeu que um sujeito criou uma clínica para ajudar pessoas com limitações físicas. Por conseguinte, as falas de suas colegas permitem uma relação com o conhecimento conceitual crítico, quando mencionam que os alunos com "limitações no jogo", ou seja, os menos habilidosos, também são excluídos ou escolhidos apenas para completar o time.

Outro exemplo da pertinência dos debates sobre a leitura das histórias em quadrinhos como elemento constituidor de conhecimento pode ser apontado na quarta aula da unidade didática de lutas, quando os alunos debateram argumentando sobre o entendimento de brigas:

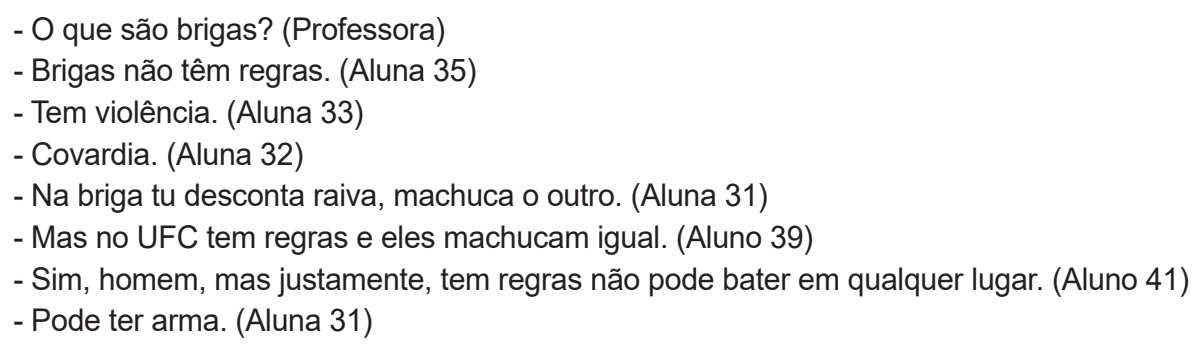

Outra evidência da contribuição do debate na reflexão e aprendizado sobre o que os alunos haviam lido nos quadrinhos consta num diálogo ocorrido na terceira aula da unidade didática de práticas corporais e saúde. Nele, nota-se que os discentes conseguiram refletir sobre o conteúdo específico da aula:

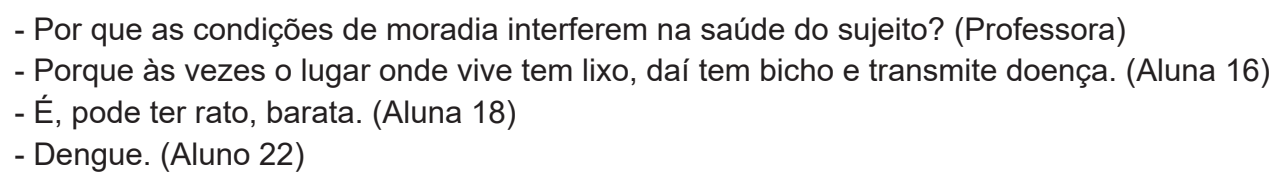

Nesse sentido, sobre o valor do conhecimento construído por meio dos debates, Ramos e Moraes (2009, p. 6) apontam que 
[...] o diálogo possibilita a confrontação com o diferente, em diferentes níveis de complexidade. Por isso, os interlocutores vão reconstruindo sentidos em relação aos fenômenos e conceitos envolvidos na interação com os outros, seja por imitação, por confrontação, por colaboração ou pela controvérsia.

A afirmação feita pelos referidos autores tem relação com os achados deste estudo. Percebemos que a ação de os alunos exporem suas ideias contribuindo - ou discordando - com as falas dos colegas, após a leitura dos quadrinhos, auxilia no aprendizado de todos, numa perspectiva colaborativa. Inclusive, identificamos alunos que também notaram que seu aprendizado foi mais significativo com a realização dos debates com os colegas, como se percebe nos seguintes trechos registrados nas avaliações escritas: "[...] é um tipo de aula diferente das aulas normais, depois de ler e falar sobre o assunto a gente memoriza mais rápido [...] um novo jeito de aprender" (Aluna 25); "A gente aprende mais debatendo com pessoas da nossa idade" (Aluna 39); "Facilitou bastante o aprendizado, porque a gente debate com o grupo" (Aluna 26); "Eu achei legal porque tipo quando uma pessoa mais velha fala a gente não é acostumado a obedecer e entender. Aí se uma pessoa da nossa idade fala em grupo a gente vai botar na cabeça e vai fazer aquilo e entender" (Aluna 2).

As manifestações dos alunos fortalecem a interpretação de que as histórias em quadrinhos contribuíram para o aprendizado à medida que se constituíram em um modo diferente e mais atrativo - em relação ao que estavam acostumados -, unindo texto e imagem num enredo que abordava conteúdos específicos da EF. Essa característica dos quadrinhos, enquanto linguagem, potencializou a participação dos estudantes nos debates com os colegas, tornando as aulas atrativas.

Finalmente, na última categoria, buscamos identificar a percepção dos alunos acerca do estudo de temas abordados por meio de histórias em quadrinhos. A maioria dos discentes considerou esse recurso interessante e/ou estimulante para estudar, conforme se identifica nas avaliações escritas: "Usar os quadrinhos para mim foi mais legal, eu entendi mais, foi um jeito diferente que usamos em aula" (Aluna 3); "Facilitou o aprendizado a leitura em quadrinhos e porque a senhora trabalhou uma história em cada aula aí ficou mais fácil de entender" (Aluna 15); "Eu gostei” (Aluno 43); "É legal porque a gente aprende sobre nossa saúde e bem-estar e é importante porque se perguntarem pra nós um dia, nós saberemos responder a pergunta do outro" (Aluna 19); "Gostei, porque eu nunca tinha visto isso" (Aluno 24).

Esse achado vai ao encontro do que Cavalcante, Novais e Ferreira (2019) identificaram, quando os alunos relataram que a utilização de histórias em quadrinhos nas aulas tornou o estudo mais interativo e dinâmico, ao passo que os autores perceberam que os discentes ficaram mais participativos nas aulas. Como Vergueiro (2016) afirma, uma das possibilidades que podem levar os alunos a terem o interesse em ler os quadrinhos é o fato de possuir uma linguagem de fácil compreensão, deixando os estudantes motivados e propensos a uma participação mais ativa nas aulas. Desta maneira, os quadrinhos podem aguçar a curiosidade dos estudantes e estimular seu senso crítico (VERGUEIRO, 2016).

Entretanto, este interesse não foi imediato. Na turma na qual realizamos as aulas de práticas corporais e saúde, os quadrinhos foram aceitos de forma lenta, com 
o desenvolver da unidade didática. Falas dos alunos antes da leitura dos quadrinhos - como: "Ah! Me dá essa coisa aqui, deixa eu ler" (Aluno 23) - permitem perceber o descontentamento em ter que realizar este tipo de atividade. A utilização deste recurso lhes exigiu concentração e reflexão no momento da leitura, pois precisavam debater posteriormente com os colegas sobre o que haviam lido. A atitude de "ter que pensar", a partir da leitura dos quadrinhos, foi um dos fatores que influenciou na resistência dos alunos, pois na maioria das aulas teórico-conceituais eles apenas faziam cópia do conteúdo.

Contudo, no decorrer das aulas os alunos começaram a aceitar a forma metodológica de estudo, percebendo que ela pode ser um instrumento que facilita a compreensão dos conteúdos. Isso fica compreensível nas falas de alguns discentes: "Eu gostei, porque a gente aprendeu bastante com as histórias em quadrinhos" (Aluna 17 - Sexta aula sobre práticas corporais e saúde); "Eu aprendi muito com as aulas e as histórias em quadrinhos... Para que servem exercícios, anabolizantes..." (Aluna 22 - Sexta aula sobre práticas corporais e saúde). Como Sousa et al. (2019) identificaram, as histórias em quadrinhos, como recurso didático usado em sala de aula, possibilitaram ampliar o aprendizado dos alunos.

Essa relevância das histórias em quadrinhos na percepção dos alunos deu-se a partir do momento em que eles: começaram a "se identificar" com os personagens; utilizaram aparelhos celulares nas aulas como recurso na busca de informações; realizaram exercícios aeróbios e anaeróbios durante as aulas e comentaram com os amigos nos corredores da escola. Assim, formas metodológicas distintas, combinadas com as histórias em quadrinhos, produziram a mudança de atitude nos alunos. Segundo Santos, Silva e Acioli (2012), as histórias em quadrinhos permitem ao leitor imaginar e participar da história. Tal imaginação, que possibilita a identificação do sujeito com os personagens, pode ser um dos fatores que estimulam a leitura dos quadrinhos e oportunizam a compreensão dos assuntos, pois quem os lê pode conseguir - através do desenho e da fala - visualizar/imaginar como esta situação seria em seu cotidiano.

Nesse sentido, a partir da leitura dos quadrinhos, os alunos conseguiram se identificar com os personagens em alguns momentos e passaram a considerar a utilização deste instrumento nas aulas como algo interessante. Assim, mesmo com a resistência inicial, os alunos reconheceram os quadrinhos como uma metodologia que facilitou a compreensão dos conteúdos, o que confirma a ideia de a leitura dos quadrinhos poder criar um ambiente de trabalho amistoso, estimulante e atraente (SOUSA et al., 2019).

Corroborando os achados neste estudo, as pesquisas de Rebolho, Casarotto e João (2009) e Amaral, Carvalho e Ribeiro (2014) apontam as histórias em quadrinhos como uma ferramenta que pode auxiliar na compreensão dos conteúdos estudados. $\mathrm{Na}$ primeira investigação, os autores constataram que os quadrinhos foram tão eficazes no aprendizado de hábitos posturais quanto as experiências práticas. $\mathrm{Na}$ segunda pesquisa, a autoria identificou a compreensão dos alunos sobre o basquetebol por meio da leitura de um gibi, de modo que todos compreenderam a leitura dos quadrinhos, $85 \%$ gostariam de vivenciar a modalidade na prática e $63 \%$ dos discentes conseguiram colocar em prática a história sobre o basquetebol. 
Nesse contexto, assim como estudos anteriores haviam identificado, esta pesquisa destaca o potencial metodológico das histórias em quadrinhos no processo de ensino e aprendizagem nas aulas de EF Escolar. Particularmente, esse recurso se mostrou eficaz no desenvolvimento de três unidades didáticas distintas uma vez que os alunos conseguiram aprender sobre os conteúdos abordados, a ponto de mencionar que gostaram da ferramenta por ser uma metodologia diferente do que eles estavam acostumados nas aulas.

\section{CONSIDERAÇÕES FINAIS}

Esta pesquisa teve o intuito de descrever as decorrências da implementação de três unidades de ensino, utilizando histórias em quadrinhos como recurso metodológico nas aulas de EF Escolar. Esse processo foi bastante complexo, particularmente pela quantidade de informações produzidas nas ações de campo, o que poderia ter sido analisado em três pesquisas diferentes de acordo com cada unidade de ensino.

Ao buscar responder o objetivo da pesquisa, identificamos que a utilização de histórias em quadrinhos como recurso de ensino foi extremamente pertinente, uma vez que possibilitou aos alunos aprender sobre os conteúdos abordados. Pontualmente, os momentos de debates entre os alunos sobre a leitura das histórias em quadrinhos constituíram-se num elemento destacado no aprendizado. Para além da aprendizagem conceitual, as próprias percepções dos alunos sobre a referida estratégia metodológica mudaram com o decorrer das aulas, passando de uma atividade entediante de se fazer, para outra, que reconhece o aspecto lúdico do recurso no processo de estudo.

Como humilde contribuição para a área, esta pesquisa fortalece a compreensão de que o ensino do conhecimento conceitual nas aulas de EF pode ser realizado de modo eficaz, por meio da utilização de histórias em quadrinhos. Tal entendimento gera uma reflexão sobre a necessidade de as instituições de ensino superior que formam professores dedicarem atenção para a abordagem dessa estratégia metodológica durante a formação inicial. Inclusive, o contato com histórias em quadrinhos na graduação pode estimular acadêmicos de EF na busca por práticas docentes inovadoras.

Como sequência desta pesquisa, pretendemos convidar um grupo de professores para, de modo colaborativo, estudar formas de utilizar as histórias em quadrinhos na EF Escolar. Com isso, buscaremos contribuir com o aumento da utilização desse recurso para potencializar o aprendizado dos alunos.

\section{REFERÊNCIAS}

AMARAL, Tamara Susan; CARVALHO, Ana Beatriz F.; RIBEIRO, Maria Aparecida. História em quadrinhos no processo de ensino e aprendizagem do basquetebol. Coleção Pesquisa em Educação Física, v. 13, n. 4, p. 83-90, 2014. 
BARDIN, Laurence. Análise de Conteúdo. São Paulo: Edições 70, 2011.

BETTI, Mauro. Mídias: Aliadas ou inimigas da Educação Física escolar? Motriz, v. 7, n. 2, jul./dez. 2001, p. 125-129.

BLUM, Leandro Carlos; MOELLWALD, Francisco Egger. História em quadrinhos como forma de ensino no EJA. In: SALÃO DE ENSINO DA UFRGS, 13., 2017, Porto Alegre. Anais [...]. Porto Alegre: UFRGS, 2017. p. 1-2.

BRASIL. Secretaria de Educação Fundamental. Parâmetros Curriculares Nacionais: Educação Física. Brasília: Secretaria de Educação Fundamental, 1997.

BRASIL. Ministério da Educação. Base nacional comum curricular: educação é a base. Brasília, 2017. Disponível em: http://basenacionalcomum.mec.gov.br/images/BNCC_20dez site.pdf. Acesso em: 02 nov. 2020.

CARVALHO, Djota. A Educação está no gibi. São Paulo: Papirus, 2006.

CARVALHO, Letícia dos Santos; MARTINS, André Ferrer. Os quadrinhos nas aulas de Ciências Naturais: uma história que não está no gibi. Revista Educação em Questão, v. 35, n. 21, p. 120-145, maio/ago. 2009.

CAVALCANTE, Willamy Oliveira; NOVAIS, Andréa Lima Ferreira; FERREIRA, Fernanda Carla Lima. Abordagem lúdica das questões de física: história em quadrinhos sobre cinemática. Scientia Plena, v. 15, p. 1-7, 2019.

COELHO, Luis Guilherme da Silva. A Geografia e histórias em quadrinhos. Revista Tamoios, v. 1, n. 1, p. 94-104, 2005.

DARIDO, Suraya Cristina. Educação Física na escola: conteúdos, duas dimensões e significados. In: DARIDO, S. C. (org.). Caderno de formação: formação de professores didática dos conteúdos. São Paulo: Cultura acadêmica, 2012. v. 6. p. 51-75.

DARIDO, Suraya Cristina; SOUZA JÚNIOR, Osmar Moreira. Para ensinar Educação Física: possibilidades de intervenção na escola. 7. ed. Campinas: Papirus, 2013.

FABRI, Eliane Isabel. Narrativas e histórias em quadrinhos: reflexões sobre o preconceito e exclusão nas práticas corporais. 2017. 121 f. Dissertação (Mestrado em Docência para a Educação Básica) - Universidade Estadual Paulista Júlio de Mesquita Filho, Bauru, 2017.

FALLEIRO, Clarissa Gabi; BITTENCOURT, Ana. A charge como instrumento de ensino de Português língua estrangeira. In: SALÃO DE INICIAÇÃO CIENTíFICA, 13, 2001. Livro de resumos. Porto Alegre: UFRGS, 2001. p. 112.

FENSTERSEIFER, Paulo Evaldo. "Produção de conhecimento e cooperação acadêmica nos países do Cone-Sul - América do Sul" - o caso da REIIPEFE. In: SILVA, P. C. C. et al. (orgs.). Territorialidade e diversidade regional no Brasil e América Latina: suas conexões com a Educação Física e as Ciências do Esporte. Florianópolis: Tribo da llha, 2016. v. 1., p. 123-136.

GIL, Antônio Carlos. Como elaborar projetos de pesquisa. 4. ed. São Paulo: Atlas, 2002.

GONZÁLEZ, Fernando Jaime; BRACHT, Valter. Metodologia do ensino dos esportes coletivos. Vitória: UFES; Núcleo de Educação Aberta e a Distância, 2012. 
GONZÁLEZ, Fernando Jaime; FRAGA, Alex Branco. Educação Física: Ensino Fundamental - $7^{a}$ e $8^{a}$ séries - Caderno do Aluno. In: RIO GRANDE DO SUL. Secretaria de Estado da Educação. Referenciais Curriculares do Estado do Rio Grande do Sul: Lições do Rio Grande: Caderno do Aluno - $7^{\mathrm{a}}$ e $8^{\mathrm{a}}$ séries - Ensino Fundamental. Porto Alegre: Secretaria de Estado da Educação RS, 2009. v. 2, p. 59-80.

GONZÁLEZ, Fernando Jaime; FRAGA, Alex Branco. Afazeres da Educação Física na escola: planejar, ensinar, partilhar. Erechim: Edelbra, 2012.

LIRA NETO, Joaquim Francisco de; ALMEIDA, Ana Paula Moreira. Gibis nas aulas de Educação Física: para uma didática crítico superadora. Relato de experiência, São Paulo, 2010, p. 1-3. Disponível em: http://www.gpef.fe.usp.br/semef2010/19-relato-JoaquimFrancisco.pdf. Acesso em: 02 nov. 2020.

LOPES DA SILVA, Cinthia et al. The effects of comic books on body beauty standards in Physical Education classes. Corpoconsciência, v. 23, p. 75-86, 2019.

MALDONADO, Daniel Teixeira et al. As dimensões atitudinais e conceituais dos conteúdos na Educação Física escolar. Pensar a Prática, v. 17, n. 2, p. 546-559, jan./mar. 2014.

MUSEU DOS GIBIS. Dedinho! Histórias em Quadrinhos para promover a prática Desportiva. São Gonçalo, 2014. Disponível em: http://museudosgibis.blogspot.com/2014/05/ dedinho-historias-em-quadrinhos-para.html. Acesso em: 18 jun. 2020.

PINTO, Joelcio Fernandes. Representações de esporte e Educação Física na ditadura militar: uma leitura a partir da revista de história em quadrinhos Dedinho. 2003. 145 f. Dissertação (Mestrado em Educação) - Universidade Federal de Minas Gerais, Belo Horizonte, 2003.

RAMOS, Maurivan Güntzel; MORAES, Roque. A importância da fala na aprendizagem: os diálogos na reconstrução do conhecimento em aulas de ciências. In: ENCONTRO NACIONAL DE PESQUISA EM EDUCAÇÃO EM CIÊNCIAS, 7., 2009, Florianópolis. Anais [...]. Florianópolis, 2009.

REBOLHO, Marilia Christina Tenorio; CASAROTTO, Raquel Aparecida; JOÃO, Silvia Maria Amado. Estratégias para o ensino de hábitos posturais em crianças: história em quadrinhos versus experiência prática. Fisioterapia e Pesquisa, v. 16, n. 1, p. 46-51, jan./mar. 2009.

RIO GRANDE DO SUL. Secretaria de Estado da Educação. Departamento Pedagógico (org.). Referencial Curricular Gaúcho: Ciências da Natureza. Porto Alegre, 2018. v. 1

SANTOS, Victor João Rocha Maia; SILVA, Fernanda Britto; ACIOLI, Monica Fagundes. Produção de histórias em quadrinhos na abordagem interdisciplinar de biologia e química. Revista RENOTE Novas Tecnologias na Educação, v. 10, n. 3, p. 1-8, dez. 2012.

SILVA, Junior Vagner Pereira; SAMPAIO, Tânia Mara Vieira. Os conteúdos das aulas de educação física do ensino fundamental: o que mostram os estudos? Revista Brasileira de Ciências e Movimento, v. 20, n. 2, p. 106-118, 2012.

SOUSA, Luciano Dias et al. Histórias em quadrinhos nas aulas de produção textual. Revista Transformar, v. 13, p. 54-66, 2019. Disponível em: http://www.fsj.edu.br/transformar/index. php/transformar/article/view/224/0. Acesso em: 8 set. 2020.

VARGAS, Tairone Girardon; MORISSO, Maríndia Mattos; GONZÁLEZ, Fernando Jaime. $O$ ensino do esporte utilizando o modelo sport education: o relato de uma experiência. In: DARIDO, S. C. (org.). Educação Física no ensino médio: diagnóstico, princípios e práticas. ljuí: Ed. Unijuí, 2017. p. 277-294. 
VERGUEIRO, Waldomiro Castro Santos. Uso das HQs no ensino. In: RAMA, Angela; VERGUEIRO, Waldomiro Castro Santos (orgs.). Como usar as histórias em quadrinhos na sala de aula. 4. ed. São Paulo: Contexto, 2016. p. 7-30.

VERGUEIRO, Waldomiro Castro Santos; RAMOS, Paulo Eduardo. Os quadrinhos (oficialmente) na escola: dos PCN ao PNBE. In: VERGUEIRO, Waldomiro Castro Santos; RAMOS, Paulo Eduardo. (orgs.). Quadrinhos na educação: da rejeição a prática. São Paulo: Contexto, 2013. p. 9-42.

XAVIER, Glayci Kelli Reis Silva. Histórias em quadrinhos: panorama histórico, características e verbo-visualidade. Darandina Revista Eletrônica, programa de pósgraduação em Letras: estudos literários, v. 10, n. 2, p. 1-20, 2018. 
Abstract: This research aims to describe the consequences of implementing three teaching units using comic books as a methodological resource in school Physical Education classes. This is a descriptive study based on a qualitative approach, in which didactic units on fighting, ultimate frisbee, and bodily and health practices were developed with three classes in the final years of Elementary School. The results indicate that the strategy of using comic books as a methodological resource was extremely productive. Specifically, students learned about the topics studied in comparison to what they knew prior to the development of the units. After reading the comics, the debates were especially important to establish conceptual knowledge. According to the students' perception, it is an interesting and stimulating resource for studying.

Keywords: Physical Education. Graphic novel. knowledge. Concept formation.

Resumen: Este estudio tiene como objetivo describir las consecuencias de la implementación de tres unidades didácticas utilizando historietas como recurso metodológico en las clases de Educación Física. Se trata de una investigación descriptiva, basada en un enfoque cualitativo, en la que se desarrollaron unidades didácticas sobre luchas, ultimate frisbee y prácticas corporales y de salud en tres cursos de los últimos años de la escuela primaria. Los resultados indican que la estrategia de utilizar historietas como recurso metodológico fue extremadamente productiva. Específicamente, los estudiantes aprendieron sobre los temas estudiados en comparación con lo que sabían antes del desarrollo de las unidades didácticas. Especialmente, los momentos de debate, después de leer las historietas fueron fundamentales en la constitución de los conocimientos conceptuales. En la percepción de los alumnos, se trata de un recurso interesante y estimulante para estudiar.

Palabras clave: Educación Física. Historieta. Conocimiento. Formación de conceptos. 


\section{LICENÇA DE USO}

Este é um artigo publicado em acesso aberto (Open Access) sob a licença Creative Commons Atribuição 4.0 Internacional (CC BY 4.0), que permite uso, distribuição e reprodução em qualquer meio, desde que o trabalho original seja corretamente citado. Mais informações em: http://creativecommons.org/licenses/by/4.0

\section{CONFLITO DE INTERESSES}

Os autores declararam que não há conflito de interesses neste trabalho.

\section{CONTRIBUIÇÕES AUTORAIS}

Kamila Isabel Trevisan: Contribuições no título, resumo, na introdução, nos procedimentos metodológicos, na análise dos dados, na conclusão e nas referências; Fernando Jaime González: Contribuições na tradução do resumo, na análise dos dados e na conclusão;

Robson Machado Borges: Contribuições no resumo, na introdução, nos procedimentos metodológicos, na análise dos dados, na conclusão e nas referências.

\section{FINANCIAMENTO}

O presente trabalho foi realizado sem qualquer apoio financeiro.

\section{COMO REFERENCIAR}

TREVISAN, Kamila Isabel; GONZÁLEZ, Fernando Jaime; BORGES, Robson Machado. Histórias em quadrinhos como recurso metodológico: uma possibilidade nas aulas de educação física. Movimento (Porto Alegre), v.26, p.e26090, jan./ dez. 2020. Disponível em: https://seer.ufrgs.br/Movimento/article/view/105484. Acesso em: [dia] [mês abreviado]. [ano]. DOI: https://doi.org/10.22456/1982$\underline{8918.105484}$

\section{RESPONSABILIDADE EDITORIAL}

Alex Branco Fraga*, Elisandro Schultz Wittizorecki ${ }^{*}$, Ivone Job*, Mauro Myskiw*, Raquel da Silveira*

*Universidade Federal do Rio Grande do Sul, Escola de Educação Física, Fisioterapia e Dança, Porto Alegre, RS, Brasil 